\title{
The world knows the real heroes after the outbreak of COVID-19 pandemic!
}

\author{
M. Kashif Iqbal, MCPS, MSc (Pain Medicine) \\ Consultant Anesthesiologist, The Indus Hospital, Karachi, Pakistan / General Secretary, Pakistan Society of Anaesthesiologists \\ (Karachi Chapter)
}

Correspondence: M. Kashif Iqbal, Consultant Anesthesiologist, T)he Indus Hospital, Plot C-76, Sector 31/5, Opposite ،Crossing ، Darussalam Society Sector 39 Korangi, Karachi, Pakistan. E-mail: dr.mkashifiqbal@gmail.com

\section{Abstract}

Over the previous few months, COVID-19 and the corona virus have become the key words in every medium of the world. Our TV screens show the ever-riding number of fresh cases and the latest mortality figures. The pandemic has affected every aspect of the human life, but it has had one positive effect; it dragged the specialty of anesthesiology and its practitioners into limelight as never before. This editorial highlights the diverse nature of the anesthesiologists' role in confronting COVID-19 and management of the patients from emergency room (ER), to intensive care units (ICUs) to operating rooms (ORs).

Key words: Anesthesiologist; Perioperative physician; Pain managers; Intensivists; COVID-19; Pandemic

Citation: Iqbal MK. The world knows the real heroes after the outbreak of COVID-19 pandemic! Anaesth. pain intensive care 2020;24(5):484-486

Received: 2 September 2020, Reviewed: 4 September 2020, Accepted: 30 September 2020

"He walks amongst us, a seemingly average person going about his daily life, but when he enters the OR, he transforms into a hero we can depend upon. With supernatural instincts, unmatched reflexes and unequaled knowledge, he exhibits outstanding performance. He is like a guardian angel that protects patients and keeps them safe during operation. He is an 'Anesthesiologist'." (Anonymous)

For many decades the herculean role of anesthesiologists remained confined to the boundary walls of the hospitals. He was a hero to many, but largely unknown to the outer world - until COVID-19 pandemic overtook the world with storm.

Historically, anesthesiologists have primarily been known as the physicians who gave anesthesia to the patients to make them unconscious and alleviate pain while undergoing surgery. With the passage of time, the domain of anesthesiologist and his role is now no longer restricted to the operating room. His canvas of activities has widened and now many new subdisciplines like critical care, pain management, resuscitation regenerative medicine and emergency medicine have firm roots in the medical practice.

Today, the anesthesiologists around the world are considered as perioperative physicians; they play active and pivotal role in resuscitation and pain management in trauma center and intensive care center as well as outside of the hospital- managing the critically sick or injured patients. The Institute of Medicine (IOM) found that, the most successful physician specialist are the anesthesiologists, who warrant patient safety and significantly have reduced mortality rate from one death per five thousand (5000) anesthesia administered to one death per two to three hundred thousand (200,000-300,000) anesthesia administered $^{1}$.

On $11^{\text {th }}$ February, 2020 the World Health Organization, declared 'COVID-19' as the official 
name of the current coronavirus outbreak. The virus causing the disease is termed as "Severe Acute Respiratory Syndrome Coronavirus 2 (SARS-CoV2).

COVID-19 badly hit the whole world, so is Pakistan. The new coronavirus is different and can be fatal. The perplexing disease course and the unpredictable response of SARS-CoV-2 has tested almost all medical specialties.

Healthcare professionals across Pakistan, like other countries, stand united in combating the COVID-19 pandemic with resolute determination and strength. When it comes to respiratory problems leading to the expertise in airway management, the role of an anesthesiologist becomes of paramount importance. As the virus is highly contagious, the airway management is the riskiest procedure,

The airway management in critically ill patients must always be considered difficult and an anesthesiologist is the right choice to handle such patients, ${ }^{2}$ being highly skilled and trained in airway management. Their exceptional skills and extraordinary intelligence when to intubate and how to ventilate make them supreme. At the same time they become vulnerable to contract the disease while performing the procedure. During intubation anesthesiologist's face is only inches away from the patient's mouth and despite of all protective measures, a minor error can lead to transfer of a massive viral load. $^{3}$ The time between intubation and tube connection to ventilator is another red zone time period when virus can become aerosolized, which is normally not airborne. In that situation there are more chances of infectious particles in air than breathing, talking, sneezing or even coughing. ${ }^{4}$ In short, there is a high risk for the anesthesiologist to contract the disease during the whole procedure of tracheal intubation that may create infectious aerosols. ${ }^{5}$

The work of the anesthesiologist is not restricted only to COVID-19 dedicated ICUs, they also work in ORs (operating rooms), non-operating room sites like imaging suits, cath labs, etc. He may be called to sedate and monitor, or to manage airway or anesthetize a COVID-19 patient. They have to work for long duty hours, risking their lives selflessly to save others. The reality is that many of them contracted the disease and some even lost their lives but they are still working as frontline soldiers. Two notable examples of corona related anesthetist mortality in Pakistan are those of Dr, Hafiz Maqsood Ali, DA, FCPS and Professor Abbas Tariq, who contracted the disease during the course of their duty and succumbed to it. ${ }^{6,7}$

Canadian Broadcasting Corporation published an investigative news story on April 2, 2020 that 9.6\% of HCWs are infected on average. However, it varies widely on regional basis from $3.7 \%$ in Toronto to $43 \%$ in Peterborough. Similarly, Spanish academic institution reported as of April 24, 2020 out of total number of infected cases in Spain $20 \%$ were HCWs. ${ }^{8}$ Furthermore, Hans news service of India published on June 1, 2020 stated that healthcare personnel in India are 33 times more vulnerable to Covid-19 than general population in India, according to a study done by ICMR (Indian Council of Medical Research). In Pakistan, data from different sources indicates that healthcare workers including anesthesiologists are losing their lives. ${ }^{9}$ As in most of the countries of the world, in Pakistan it is the anesthesiologists who are deputed to manage the ICUs in most of hospitals.

Studies show highly negative outcome of COVID-19 patients requiring intubation which is really distressing. ${ }^{10}$ One can imagine the level of grief and stress of an anesthesiologist watching his patient succumb to the virus for which he had put himself in danger. On the other hand, there is an inherent risk to take the virus to their homes and transfer the virus to their loved ones, all these factors inevitably lead to mental stress for all healthcare workers.

Despite all of the known risks, our friends continue to fight against this invisible enemy with courage; pushing the limits with limited resources. The hard work and dedication shown by the anesthesiologists has been incredible.

The anesthesiologist, are proud to be on the frontlines of the war against the deadly microorganism, and play an active role in saving human lives and now the World knows them as heroes.

\section{Conflict of interest}

The author declares that there is no conflict of interest

\section{References}


1. Lanier WL. A three-decade perspective on anesthesia safety. Am Surg. 2006 Nov;72(11):985-989. [PubMed] DOI: $10.1177 / 000313480607201101$

2. Walz JM. Point: Should an anesthesiologist be the specialist of choice in managing the difficult airway in the ICU? Yes. Chest. 2012 Dec;142(6):1372-1374. [PubMed] DOI: 10.1378/chest.12-2194

3. American Society of Anaesthesiologists, ASA Committees, Committee On Occupational Health, Recommendations - When considering a procedure for a patient with known or suspected COVID-19 infection; Available from: https://www.asahq.org/aboutasa/governance-and-committees/asacommittees/committee-on-occupationalhealth/coronavirus

4. US Centers for Disease Control and Prevention, COVID-19 infection prevention and control in, healthcare settings: questions and answers. Accessed April 11, 2020. Available from: https://www.cdc.gov/coronavirus/2019ncov/hcp/faq.html

5. Weissman DN, de Perio MA, Radonovich LJ Jr. COVID-19 and Risks Posed to Personnel During
Endotracheal Intubation. JAMA. 2020 May 26;323(20):2027-2028. [PubMed]

DOI: $10.1001 /$ jama.2020.6627

6. Khan MA. Hafiz Maqsood Ali, DA, FCPS (Obituary). Anaesth Pain Intensive Care. 2020:24(3):30. [Free full text] DOI: $\underline{10.35975 / a p i c . v 24 i 3.1292}$

7. Ashraf MS. Professor Abbas Tariq (Obituary). Anaesth Pain Intensive Care. 2020:24(3):372. [Free full text] DOI: 10.35975/apic.v24i3.1295

8. Are healthcare workers at increased risk of COVID-19 Rapid Review, COVID-19 Scientific Advisory Group Rapid Response Report, Alberta health services Canada; May 4, 2020. Available from: https://www.dawn.com/news/1563090

9. Walker M. High Mortality Rate in Intubated COVID-19 Patients in NYC. MedPage Today. 2020 April 22; Available from: https://www.medpagetoday.com/infectiousdisease/co vid19/86101

10. Swift D. Higher Mortality Rate in Ventilated COVID-19 Patients in Large Sample. Medscape Medical News, April 13, 2020. Available from: https://www.medscape.com/viewarticle/928605 